\title{
DICTIONARY OF RELATIONAL SOCIOLOGY
}

\section{PAOLO TERENZI, LUCIA BOCCACIN, RICCARDO PRANDINI \\ [EDS.], LESSICO DELLA SOCIOLOGIA RELAZIONALE}

Elżbieta Hałas

University of Warsaw

A dictionary of relational sociology immediately raises questions: what is it, what does it mean, and what are its uses? Some helpful suggestions are present in the dictionary's preface, written by its three editors. Relational sociology, systematically developed since the early 1980s in accordance with the paradigm initiated by Pierpaolo Donati, has become a prolific research orientation in Italy and is described as the Italian relational turn. It is being creatively developed by many researchers, including the authors of entries in the dictionary, which serves as a guide to relational sociology as understood by Pierpaolo Donati. Among the 26 authors, who are of different generations and are all well-known scholars and researchers, 13 are associated with the University of Bologna. Hence, we may use the term "Bologna school of relational sociology," since that is where this current was initiated and then evolved in the circle of its creator. A glance at the alphabetical list of entries is sufficient to note that the dictionary establishes a new conceptual grid, often by adding the adjective "relational" to various terms. This is obviously a manifestation of the new way of theorizing. Examples include "Relational contracts," "Relational differentiation," "Relational education," and "Relational reason." Entries pertaining to the widely accepted vocabulary of sociology are relatively few in number. Moreover, the reader finds that concepts such as "association," "communication," or "socialization" have also acquired a new relational sense. Among the concepts of classical sociology, the fundamental distinction between Gemeinschaft and Gesellschaft has been interpreted anew. It serves as an example of 
"revisiting" classic works to once again pursue sociology as a science about society understood as networks of relations (Terenzi et al. 2016: 99). Entries such as "Social risk," "Social capital," "Interculturalism and multiculturalism," and "Social morphogenesis" show that relational sociology takes up key problems discussed in various contemporary sociological theories of postmodernity and late modernity, as well as in other works about modern socio-cultural transformations. The relational angle shows these issues in a new light, while the concept of the dopo-moderno (after-modern), discussed in a separate entry, thematizes these changes in a distinct, innovative way. The tissue of social relations makes it possible to combine the concepts of social networks and everyday life (both of which are included in the Lessico...), even though they have hitherto been associated with two different theoretical currents. Of course, basic concepts, such as the entries on "Social relation" and "Reciprocity," play a fundamental role. Obviously, we will not list all the entries here, or even exhaustively group them. However, those that relate to the public sphere, civil society, the third sector, social work, and social policy should be mentioned. All this serves to highlight the practical orientation of relational sociology.

The dictionary has appeared at a time when the term "relational sociology" is spreading rapidly in scholarly publications around the world (Porpora 2015: 182-189). Importantly, the meanings given to it are often imprecise, blurring the original sense ascribed to this term by Italian sociologists. In response to the pressing need for a clearer formulation, a special issue of the "International Review of Sociology" appeared in 2015, edited by Riccardo Prandini and dedicated entirely to relational sociology (Prandini 2015). In that issue, Pierpaolo Donati published a policy paper that showed Mustafa Emirbayer's failure to correctly use the concept of relationality. Emirbayer's manifesto has caused many misunderstandings (Donati 2015; Emirbayer 1997). Thus, an English edition of this dictionary would obviously help ensure that the worldwide development of relational sociology proceeds in the right direction.

The dictionary's aim is to show the three pillars of relational sociology: the ontological and epistemological premises upon which the morphogenetic theory of social phenomena is founded, the methodology of empirical research, and the so-called "application pragmatics" - in other words, the application of relational sociology, especially in the field of broadly understood social policy. The basic premise states that "at the beginning (of any social reality) lies the relation" (Terenzi et al. 2016: 9). The Lessico... explains that relational sociology does not reject classical sociology; on the 
contrary, it articulates its legacy anew. This reformulation leads to the formation of a new, unique methodology that will function as the path to relational cognition. Empirical analyses become the standard for testing relational sociology. The ultimate aim is social intervention, but in a form completely different from modernist social engineering.

The entries in Lessico della sociologia relazionale represent an introduction to the theory and methodology of relational sociology, while simultaneously showing their usefulness in empirical research and the practical consequences as regards various areas and problems of social life.

The lexicographic arrangement of each entry is exceptionally original and consists of three sections: an exposition of the concept, which contains unambiguous definitions proposed by Pierpaolo Donati and an account of their evolution over time; then references to Donati's works on the given topic (up to five for each entry), which enable the reader to trace the development of each concept; and finally, creative elaboration of the topic by other authors (also up to five selected works). A bibliography of Pierpaolo Donati's works (published between 1971 and 2015) has been placed at the end of the dictionary. It contains 787 titles published over more than 40 years. Thus, the Lessico... presents the achievements of the representatives of Italian relational sociology, but above all, it is a guide to the monumental scholarly legacy of its creator, Pierpaolo Donati, while also being a tribute to his work.

It is worth noting that the Lessico... has had a prototype in the form of a glossary included in the volume Sociologia. Una introdurione allo studio della società (Donati 2006a). This glossary contains the definitions of basic concepts in relational sociology. The Lessico... is an excellent introduction to relational sociology, especially since its form is conducive to non-linear reading and enables the reader to take various paths when exploring the territory of relational sociology. A certain redundancy of information in the form of essential repetitions in entries that constitute separate wholes makes this easier still.

One type of entry merits particular attention: entries that contain two related concepts, e.g., "Sociologism/Relationism" or "Relational subject/ Social subjectivity." Although the entire dictionary is dedicated to relational sociology, no entry presents the premises of this current in a synthetic fashion. Hence, the critique of sociologism and relationism enables us to determine the premises of relational sociology through negation: by discarding all those elements of former and modern sociological approaches that are considered an encumbrance or ballast. Criticism of sociologism is, 
of course, nothing new. It has a long tradition, originating from numerous polemics with Émile Durkheim's concept of the social fact. In recent times, Raymond Boudon, among others, has voiced this kind of critical opinion afresh (Boudon 1979). Donati's relational sociology differs in its focus and aims from Boudon's theory of individual action, which was initially directed against sociologism understood as a radical standpoint attempting to explain social phenomena only through social phenomena. Thus, this critical starting point proves to be a crucial matter, as the issue of the novelty and originality of relational sociology as a theoretical proposition must inevitably arise, given that this current has emerged precisely from the critique of sociologism and its ontological assumptions. Paolo Terenzi, the author of the entry Sociologismo/Relazionismo, emphasizes that Donati's relational sociology represents an alternative possibility, especially in regard to the particular kind of sociologism present in theories of social reproduction. Thus, the anti-sociologism of relational sociology consists of rejecting a concept of man and society where social actions and events are understood and explained through the prism of determinist factors belonging to a collective order, either structural or cultural in character. At its beginnings, Donati's relational sociology is more or less convergent with other orientations characterized by criticism towards Talcott Parsons's structural functionalism. These orientations can be as varied as symbolic interactionism or Margaret S. Archer's morphogenetic theory. While a critique of the over-socialized concept of man as a "gift of society" (to quote Margaret S. Archer) seems only a variation on the topic taken up and deeply analysed by many authors, raising the issue of relationships between empirical reality and values, especially moral values, appears to supply novel viewpoints and noteworthy arguments in the discussion with sociologism.

Relational sociology has challenged sociologism (Terenzi et al. 2016: 300 ) on the grounds of sociological discourse, rather than philosophical discourse or some other type of discourse. A critical point in Donati's relational sociology is the postulate of breaking away from the amoral nature of sociology, understood as freedom from valuation. In other words, he presents the controversial project of turning sociology into some kind of moral science, as well as a new form of political thought. Some premises of relational sociology must obviously provoke discussion, e.g., its criteria for the moral evaluation of observed social facts and for formulating visions of how reality may be transformed. In particular, it is doubtful whether the positions that remain faithful to the postulate of freedom from valuation should be classified as examples of sociologism, since searching for valu- 
ation criteria on the grounds of sociology itself, even relational sociology, may be a sign of sociological reductionism, and thus effectively of sociologism, to which relational sociology is opposed. It seems that the postulate of creating relational anthropology may be a way to escape this trap (ibid.). It should be noted that the dictionary contains no overview of the concept of relational sociology in a separate entry. Such a synthetic characterization would certainly prove very useful. There are also no entries on ethics, morality, or values, which (considering the sensitive issue of the controversial relationships between sociology and ethics) seems a serious deficiency, one that should, perhaps, be remedied in subsequent editions.

The critique of sociologism under various forms of social reproduction, which reify social institutions, has been extended to new orientations, which have begun to be called relational, and which Donati calls relationist. The critique of relationism was initially directed against Karl Mannheim's sociology of knowledge. For Mannheim, knowledge is a purely socio-cultural construct. Donati subsequently began using the term "relationism" to refer to the so-called relationist sociologies of Mustafa Emirbayer, Jan Fuhse, Nick Crossley and others. He emphasizes the contrast between relational sociology, based on the ontology of critical realism, and relationism. It is very important to understand the distinction between relationism and relationality. Relationality means a definite rejection of the mere processuality of relations, one-sidedly emphasized by relationists, in favour of a proper analysis of emergent reality; in other words, of the specific reality of social phenomena as the relations between entities, where the relation perceived as a process also has its own structure.

The entry "Person" evokes the promising possibilities offered by relational anthropology. Both the new way of perceiving anthropology and the innovative character of the relational concept of the human person will certainly serve as a focus for a critical study of this approach, given e.g., the wealth and diversity of existing personalistic anthropology, as well as the earlier presence of the concept of the person in social theory, to mention only the works of Marcel Mauss, Pitirim A. Sorokin, or Florian Znaniecki. Later on, this concept became less visible. For several decades of the twentieth century, sociology tended to focus on the actor, agent, or at best the Self, until the concept of the person finally came back into favour in the twenty-first century. Christian Smith's book is a good illustration of this trend (Smith 2011). The observation that Donati did not deal systematically with the theory of the person (Terenzi et al. 2016: 175), articulating the implicit understanding of the human person as a relational subject only 
in his commentary on the position of Margaret S. Archer (Donati 2006b), raises the following question: what elements of relational sociology would hold important implications for the new anthropology? Apparently, it is necessary to define the essential conditions for the emergence of social forms that can be considered human as long as relations are created by reciprocally oriented subjects and the human quality of relations consists of respect towards the Other (Terenzi et al. 2016: 178).

A critical distance to the metaphysical notion of the person, but also to the transplantation of any other philosophical anthropology into the social sciences, is associated with an attempt to carry out an integral project involving relational ontology, social relations theory, research methodology (relational analysis), and a political project in a broad sense-involving social work, among other things. The concept of the person is supposed to enable us to take a fresh look at the relation between the person and society, as well as, on a methodological level, to solve the conflict between individualism and holism, and on a political level, the conflict between a liberal and socialist (collectivist) interpretation of civil rights (the liberal market versus the welfare state and the labour force: "lib/lab," to quote Donati). Each of those dichotomous positions essentially eliminates social relations and the person as an individual-in-relations. Hence, the relational approach is intended to allow linking the person with society, as long as both entities maintain their respective specific realities and autonomy. In this perspective, the person appears as a relationally constituted being who constantly transcends the relations he or she generates, while simultaneously remaining a subject in interactions - also capable of building relations with himor herself. As the reality of social relations cannot be brought down to communication processes, the relational concept of the person extends far beyond the conceptualization of the semiotic or dialogic Self. However, this concept requires further theoretical elaboration, taking into account the differences and links between the person and the Self, especially since relational sociology has taken up the issue of reflexivity, which has been so important for the theory of the Self ever since the works of Charles H. Cooley and George H. Mead appeared.

The conceptual frames reflected in the Lessico... naturally represent only what is most significant in the theoretical vocabulary of relational sociology. It turns out that issues of social subjectivity, considered in regard to the person as a relational subject (as illustrated by the double entry "Relational subject/Social subjectivity"), prove particularly important for this theory. The above-mentioned double entry contains the concept of the re- 
lational "I," which, unlike the Self, redefines itself through relations. Subjectivity is expressed through identity; Donati presents a relational model of the latter. However, the concept of the Self, particularly the dialogical Self, apparently cannot be marginalized in this theory, since the abovementioned problem of reflexivity needs to be taken into account. Donati elaborates reflexivity as relational reflexivity, which (like relational identity) is discussed in a separate entry.

The relational subject exists only in relations and is constituted through relations. The concept of the relational subject pertains not only to persons. It holds significance in regard to collective subjects, enabling us to better understand the social subjectivity of various social formations arising from the relationality of persons on the micro-social level (sociology of everyday life). Social subjectivity subsequently develops on the meso and macro levels. Social subjectivity is distinguished from the concept of the collective actor, as it manifests itself in the forms of association of individuals or groups (individual actors and collective actors) in which the common identity is linked with the participants' freedom and responsibility.

It is a paradox of sorts that Donati's relational sociology, despite originating from a negation of Talcott Parsons's structural functionalism and neo-functionalism (especially of Niklas Luhmann), uses a heuristic tool based on the AGIL scheme, which has its own entry in the Lessico... However, in Donati's interpretation, the four structural requirements (Adaptation, Goal Attainment, Integration, Latency) take on a whole new meaning and become imbued with new content, preserving only the logical and analytical form of AGIL. As generalized components of action, they are: the means (tools), the goal, the norm, and the value model. In other words, the AGIL scheme refers to the means and instrumental resources, the intent or situational goal, normative regulation, and the cultural model of values. This heuristic scheme of relational sociology, which emphasizes the social context and situation, is described as a kind of methodological compass, making it possible to orient the analysis of social facts as emergent phenomena in the processes of morphostasis or morphogenesis. In particular, it represents constitutive dimensions of the analysis of social relations. This interpretation is critical both in regard to Niklas Luhmann's theory, where the AGIL scheme is an autopoietic mechanism of the social system (Terenzi et al. 2016: 269) and in regards to Parsons's approach (functional requirements). This scheme contains no postulates; it is merely an instrument enabling us to study the actual configurations of the dimensions of social relations. It is a way of con- 
ducting observations, a tool for studying the relational order as the basis of every social structure.

It is worth noting that the Lessico... does not contain separate entries interpreting social action or interaction from the perspective of relational sociology, although "relation dynamics" and emergence are continually emphasized. The latter is not discussed in a separate entry either. Admittedly, in Donati's interpretation the AGIL scheme proves exceptionally effective from an analytic point of view, as shown, e.g., by the entries: "Solidarity" (types of solidarity; solidarity as the redistribution of resources and means; solidarity as sharing common ideals and interests; solidarity as the social norm of reciprocity of gifts (symbolic exchange); and solidarity as confirmation of the unity of a human community according to the AGIL analytic paradigm (Terenzi et al. 2016: 311)) or "Relational reflexivity" (ibid.: 240-249), which distinguishes the following types of this phenomenon-instrumental reflexivity, value-oriented (autonomous) reflexivity, relational (communicative) reflexivity, and meta-reflexivity understood as value reflexivity. On a purely lexical level, some of the terms are identical with those used by Margaret Archer (2012); however, she utilizes a different concept of reflexivity types, although both concepts are theoretically coherent and rooted in relational sociology.

The AGIL scheme can be applied in analysis from a viewpoint that is either internal or external in respect to the relation; in other words, from the standpoint of the acting subject and the subject's intentions in the given relation or in respect to other relations. In the second case, the analysis is performed in such dimensions as heteronomy, instrumentality, autonomy, or selflessness. Thus, AGIL becomes an instrument that enables us to study social processes which generate social facts. These facts are explained and interpreted as an emergent relational effect.

Readers are tempted to ask what distinguishes relational sociology from other sociological theories, both classical and new, as regards the kind of cognition it proposes. The opening entry in the Lessico..., Analisi relazionale ("Relational analysis"), contains important clues to the answer. This entry proves particularly helpful in avoiding the confusion which may be caused by the apparently central role of the AGIL scheme, associated mainly with functionalism (Talcott Parsons's Grand Theory). Relational analysis is part of the relational cognitive system, which contains the following components: approach, theory, paradigm, and method. The relational approach consists of adopting the optics of relationality, which makes it possible to distance oneself both from individualism and from holism by focusing on 
the social relation as an elementary social fact. The aim of the constructed theory is to understand and explain social phenomena as phenomena generated by social relations. The relational paradigm is based on the concept of society as a network, whereas the research methodology depends on relational analysis. Interestingly, relational analysis is seen as a way towards developing an interpretative theory of social phenomena in the light of the relational approach, utilizing various heuristic models such as the modified AGIL model or the model of social relations as refero-religo (the psycho-cultural dimension of meaningful orientation and structural ties). However, although interaction is so important for the interpretative paradigm, it does not appear to be explicitly thematized, despite being an inherent part of any relation in actu. As mentioned earlier, an entry on interaction has not been included in the Lessico.... This only serves to highlight the distinctiveness of the relational paradigm and the main idea of society as a social relation, rather than society as symbolic interaction. (This latter view was favoured by Herbert Blumer, who emphasized the importance of the interpretative process of creating and negotiating meanings in establishing social order.)

The stages of relational analysis, and therefore of the methodological approach, have been described in detail. Without going into specifics, it should be noted at this point that relational analysis begins with choosing between descriptive observation or problematizing observation. The target stage of analysis is the application, and therefore the implementation, of the Observation-Diagnosis-Guidance (ODG) formula. Thus, relational analysis combines the theory and pragmatics of social intervention. Here, again, the sensitive issue of valuation in sociology comes up. The position of relational sociology articulated by Donati seems as refined as it is ambivalent: he describes relational sociology as a positive science, based on facts, but not positivist (Terenzi et al. 2016: 18). Moreover, it should be hermeneutically adequate, which may also be interpreted as a postulate to include the experience of values, including moral values. The postulated obligation of the sociologist to ascribe the proper ethical value to the facts in question and to explicate the ethics on the basis of which they are judged, and hence the postulate of questioning the positivist separation of facts and values, is not an excuse for confusing sociology with ethics. Postulates of this sort certainly make the sociologist's task extremely complex as compared to the simpler choices of either complete neutrality or determined commitment. Relational sociology undoubtedly prompts us to rethink the differences and relationships between sociology and the moral sciences. It reconstructs and transforms sociology as a systematic undertaking. It is founded on the 
new semantics of identity, the conceptualization of reciprocity, and above all the analysis of social relations as reality sui generis, the distance that simultaneously distinguishes and links together the ego and alter. The carefully elaborated Lessico... is certainly a significant achievement for Italian scholars and an important step towards establishing relational sociology as a methodical undertaking, axiologically oriented towards relational goods.

Bibliography:

/// Archer M.S. 2012. The Reflexive Imperative in Late Modernity, Cambridge University Press.

/// Boudon R. 1979. La logique du social. Introduction à l'analyse sociologique, Hachette.

/// Donati P., ed. 2006a. Sociologia. Una introdurione allo studio della società, CEDAM.

/// Donati P. 2006b. Understanding the Human Person as a Relational Subject: An "After" Modern Paradigm for the Social Sciences (or: The "Economy" of Human Persons Lies on Their Ultimate Concerns, [in:] Conceptualization of the Person in Social Sciences, eds. E. Malinvaud, M.A. Glendon, The Pontifical Academy of Social Sciences, pp. 284-295.

/// Donati P. 2015. Manifesto for a Critical Realist Relational Sociology, "International Review of Sociology", vol. 25(1), pp. 86-109.

/// Emirbayer M. 1997. Manifesto for a Relational Sociology, "American Journal of Sociology", vol. 103(2), pp. 281-317.

/// Porpora D.V. 2015. Reconstructing Sociology: The Critical Realist Approach, Cambridge University Press.

/// Prandini R.R. 2015. Relational Sociology: a Well-Defined Sociological Paradigm or a Challenging "Relational Turn" In Sociology? "International Review of Sociology”, vol. 25(1), pp. 1-14.

/// Smith Ch. 2011. What Is a Person?: Rethinking Humanity, Social Life, and the Moral Good from the Person Up, The University of Chicago Press.

/// Terenzi P., Boccacin L., Prandini R., eds. 2016. Lessico della sociologia relazionale, il Mulino. 
/// Elżbieta Hałas - full professor of humanities and sociology at the Institute of Sociology, University of Warsaw, Poland. Her fields of interest are theory of culture and cultural sociology, social symbolism, symbolic politics and cultural memory, symbolic interactions, and social relations. Her research is focused on the problems of contemporary cultural transformations. She received a Fulbright Award and was a fellow of the American Council of Learned Societies (USA) and the Institute of Human Sciences (Vienna, Austria). She served two terms on the Executive Committee of the European Sociological Association (1999-2003). She is the author of many publications in international journals, as well as multiple books, including: Przę pryzmat kultury. Dylematy badań nad wspótczesnościa [Through the Prism of Culture: Dilemmas of Research on Contemporaneity] (2015), Towards the World Culture Society: Florian Znaniecki's Culturalism (2010), Symbole i spoteczeństwo [Symbols and Society] (2007). She is the founder and co-editor of the book series "Studies in Sociology: Symbols, Theory and Society." E-mail: ehalas@uw.edu.pl 
